\title{
Correlation between gross morphology of the human placenta and birth weight in normotensive and pre-eclamptic pregnancies in Northwest Ethiopia
}

\author{
Shibabaw Tedla Tiruneh \\ Department of Human Anatomy, School of Medicine, College of Medicine and Health Sciences, Babir Dar University, Babir Dar, Ethiopia
}

\begin{abstract}
Objectives: The objective of this study was to investigate correlation of gross morphology of human placenta with birth weight in normotensive and pre-eclamptic pregnancies obtained from Bahir Dar, Northwest Ethiopia.

Methods: Institutional based comparative cross-sectional study was carried out on 200 term placentas (37 to 42 weeks of gestation) between October and January 2015. 150 placentas from normotensive and 50 from pre-eclamptic pregnancies were collected and examined for weight, diameter, thickness and number of cotyledon. Birth weight and placental-fetal weight ratio also measured.

Results: The mean birth weight in pre-eclamptic pregnancies $(2.6 \mathrm{~kg})$ was significantly $(\mathrm{p}=0.0001)$ reduced as compared to birth weight $(3.1 \mathrm{~kg})$ in normotensive pregnancies. However, placental-fetal weight ratio had no significant $(p=0.658)$ difference between normotensive (6.34:1) and pre-eclamptic (6.41:1) groups. Birth weight was correlated with placental weight ( $r=0.572)$, diameter $(r=0.583)$, thickness $(r=0.192)$ and number of cotyledons $(r=0.647)$ in the pre-eclamptic group. Birth weight was also correlated with placental weight $(r=0.572)$, diameter $(r=0.583)$, and number of cotyledons $(r=0.647)$ in the normotensive group. However, no correlation was found between placental thickness $(r=0.192)$ and birth weight in the normotensive group.

Conclusion: Birth weight was significantly reduced in pre-eclamptic pregnancies as compared to normotensive pregnancies. Morphology of placenta such as weight, diameter and number of cotyledons were correlated with birth weight in both groups, but placental thickness was only correlated with birth weight in pre-eclampsia, but not in normotensive group. Placental-fetal weight ratio had not significant difference between the groups. Examination of placental morphology prenatally using ultrasound and observation immediately after delivery is important for better management of this and subsequent pregnancies.
\end{abstract}

Keywords: birth weight; morphology; placenta; pre-eclampsia

Anatomy 2018;12(1):27-32 @2018 Turkish Society of Anatomy and Clinical Anatomy (TSACA)

\section{Introduction}

The placenta is temporary vital organ situated between mother and developing fetus until the end of pregnancy. ${ }^{[1]}$ It is the fusion of feto-maternal tissue derived from decidual basalis and villous chorion, respectively. ${ }^{[2]}$ Placenta is sentinel predictor of the intrauterine health status of fetus. ${ }^{[3,4]}$ It acts as vital body organs like the lung, kidney, heart and digestive organs for transfer of nutrients and gases from the mother to the fetus; removal of waste prod- ucts from the fetus to the mother. It is also a temporary endocrine organ that produces hormones for maintaining pregnancy. ${ }^{[5-7]}$ The healthy survival of fetus depends on the placenta for normal growth and development. ${ }^{[8,9]}$ Fetal weight is a very useful determinant of fetal survival, healthy growth and development ${ }^{[8]}$ and is directly associated with placental morphology. When the formation, growth and functioning of placenta are compromised by diseases, maternal and fetal well-being fall at risk. ${ }^{[10]}$ At term, the normal human placenta is discoid in shape, 500 
$\mathrm{g}$ in weight, $18.5 \mathrm{~cm}$ in diameter, $2.5 \mathrm{~cm}$ thick and has 15 to 30 number of cotyledons. ${ }^{[11]}$ These features of human placenta can be affected by pre-eclampsia. Pre-eclampsia is a pregnancy related metabolic disease which affects the placenta macroscopically as well as microscopically. ${ }^{[12]}$ It is described as the occurrence of new onset of elevated blood pressure in previously normal pregnant women after 20 weeks of gestation. Pre-eclampsia complicates 5 to $10 \%$ pregnancies world-wide ${ }^{[13]}$ and is a major contributor for maternal and child morbidity and morbidity. ${ }^{\left[{ }^{5}\right]}$ In developed countries like Ethiopia, the health care system is overwhelmed by preventive, control, investigation and therapeutic challenges of pre-eclampsia. Even though placenta is important for the survival and wellbeing of the fetus and mother, the influence of it on placenta, fetus and mother has not been well investigated. Immediately after delivery, the placenta is discarded as a waste without examining its morphology, as well as its relation with birth weight. Placental morphology and its association with birth weight are under-investigated also in Ethiopia. With these view, this study aimed to assess the correlation between gross morphology of human placenta and birth weight in Northwest Ethiopia.

\section{Materials and Methods}

This institutional based comparative cross sectional study was conducted between October and January 2015 in Gondar, Northwest Ethiopia. The study participants were term pregnant women who attended labour at obstetrics ward during the study period. Those normal and preeclamptic women were included in the study. Normotensive women were pregnant mothers who were diagnosed as normal or without pre-eclampsia and other acute and chronic diseases. Pre-eclamptic women were pregnant mothers who were diagnosed with pre-eclampsia, but free of other acute and chronic diseases. The diagnosis of pre-eclampsia was based on one or more of pre-eclampsia diagnostic investigations, i.e. new onset of elevated blood pressure and presence of proteinuria in urine microscopy.

The study was designed to have $80 \%$ statistical power with level of significance at $5 \%$ and normotensive to preeclampsia ratio of 3:1. Sample size was estimated using mean difference formula by taking the mean of placental weight $(478.8 \mathrm{~g})$ among normotensive and $(385.4 \mathrm{~g})$ among pre-eclamptic mothers. The variances of placental weight were 292.12 among normotensive and 82.21 among pre-eclamptic mothers. The calculated sample size was 200 (150 for normotensive and 50 for pre-eclampsia). The sample size was also calculated for placental diameter, thickness, number of cotyledons and birth weight, and the largest sample estimate was taken. At the University of
Gondar Referral Hospital Obstetric Ward, Gondar, Ethiopia, approximately a total of 20 normotensive mothers were giving birth per day. We used systematic random sampling with sampling interval of five to select normotensive mothers. All pre-eclamptic mothers who were attending labour during the study period were included.

A total of 200 term placenta (150 from normotensive and 50 from pre-eclamptic mothers) were collected immediately after delivery at the obstetrics ward. The collected placentas were checked for their completeness, and trimmed membrane. Then placentas were washed with tap water to remove any blood clot and prepared for measurement.

Placenta weight and birth weight were measured by directly placing the placenta and newborn over standardized weight scale.

To measure the diameter of the placenta, the placenta was placed in a flat tray after trimming the membrane. The first maximum diameter was measured with a plastic measuring scale graduated in centimeter, then the second maximum diameter was taken at right angle to the first one (Figure 1). The mean of the two measurements was considered as the diameter of the placenta.

Placental thickness was measured at five points using a long needle. The placenta was divided into three equal parts by drawing two circles on the maternal surface of the placenta. These circles cut the radius of the placenta into three equal parts. One thickness was measured from the center of central zone, two from the middle zone and two from the peripheral zone. The peripheral points were

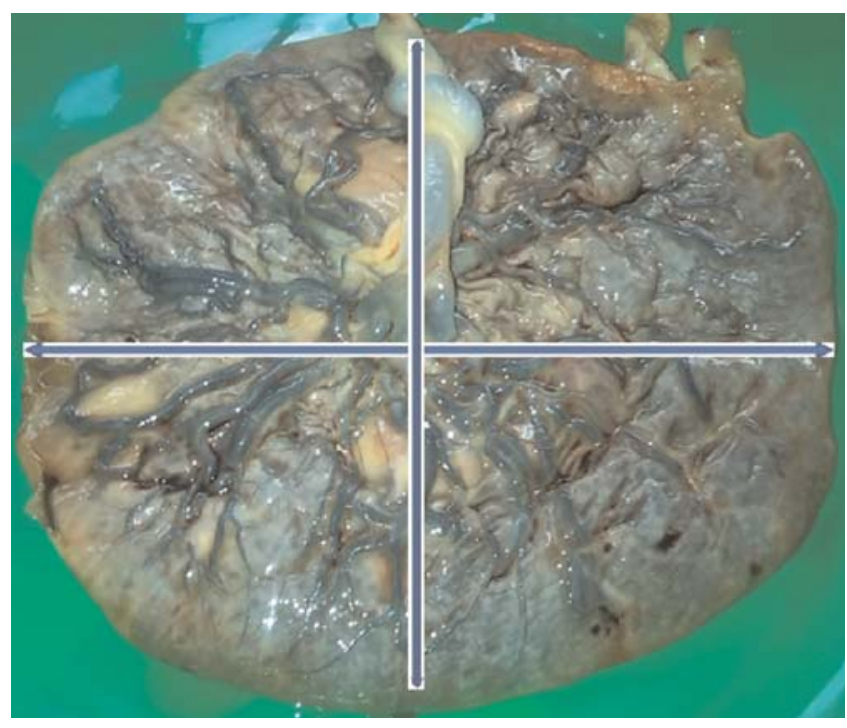

Figure 1. Measurement for diameter of the placenta. [Color figure can be viewed in the online issue, which is available at www.anatomy.org.tr] 
taken within the outer zone on a line perpendicular to the previous imaginary line in the middle zone (Figure 2). Finally, the mean of all five measurements were calculated as the thickness of the placenta.

The placenta was placed in $10 \%$ formalin solution for $24 \mathrm{~h}$ in order to make the placenta groove visible to count the cotyledon. Then, gentle pressure was applied on the center of the fetal surface of the placenta. As a result, the cotyledon on the maternal surface became prominent. The placenta was placed on a fetal surface with maternal surface facing upward. Counting of the cotyledon was started from the left side of the one end of the placenta and then going to the right and again turning back to the left in a loop (Figure 3). Finally, total number of cotyledons was counted and recorded.

Data were entered into Epi statistical software for epidemiology version 7 (Atlanta, GA, USA) and analysis was done by using IBM SPSS Statistics for Windows (Version 20, Armonk, NY, USA). Frequencies and proportions were used to describe the study subjects in relation to the studied variables. A value of $\mathrm{p}<0.05$ was used to identify statistical significant results. Pearson correlation test was used to investigate correlation of birth weight with placental morphology in normotensive and pre-eclamptic pregnant mothers.

Ethics approval a was obtained from the Ethical Review Board of School of Medicine, College of Medicine and Health Sciences, University of Gondar, Gondar, Ethiopia. Communication with the Department of Obstetrics and Gynecology was made through a formal letter obtained from Department of Human Anatomy.

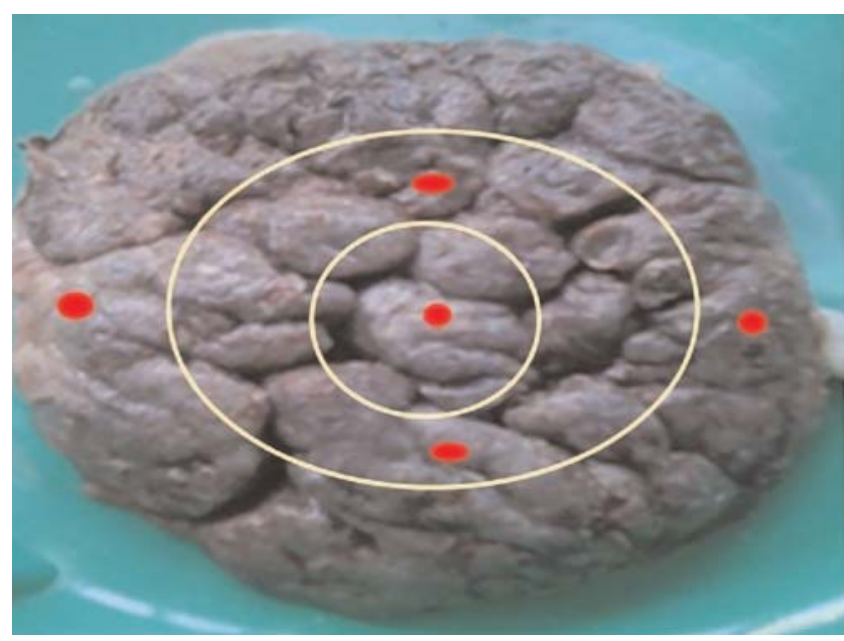

Figure 2. Measurement points for placental thickness. [Color figure can be viewed in the online issue, which is available at www.anatomy.org.tr]
After the purpose of the study was informed, written consent was obtained from each participant. Confidentiality was maintained by making the data collection anonymous. Participation was on voluntary basis.

\section{Results}

In this study, $43.3 \%$ of study subjects were in the age group 18-25 years among normotensive mothers, while $54 \%$ of study subjects were in the age group of $18-25$ years in pre-eclamptic mothers. Among pre-eclamptic mothers, $54 \%$ were primigravida and $46 \%$ were multigravida. Similarly, $49.3 \%$ study subjects were primigravida and $50.7 \%$ were multigravida among normotensives. Among 150 normotensive placentas, majority $(78.7 \%)$ was delivered by spontaneous vaginal delivery, $6.6 \%$ by assisted forceps delivery, and $14.7 \%$ by cesarean section. Likewise, of 50 pre-eclamptic placentas, $52 \%$ were delivered by spontaneous vaginal delivery, $10 \%$ by assisted forceps delivery and $38 \%$ by cesarean section (Table $\mathbf{1}$ ).

In normotensive and pre-eclamptic groups, mean fetal weight was $3.1 \mathrm{~kg}$ and $2.6 \mathrm{~kg}$, respectively. The difference was highly significant $(\mathrm{p}=0.0001)$ (Table 2$)$.

From normotensive groups, $96 \%$ of the newborns placental weight was more or equal to $2.5 \mathrm{~kg}$ and in $4 \%$ less than $2.5 \mathrm{~kg}$, while in pre-eclampsia, in $62 \%$ of the newborns placental weight was more or equal to $2.5 \mathrm{~kg}$ and in $38 \%$ less than $2.5 \mathrm{~kg}$ (Table 3). Normal birth weight is between $2.5-4 \mathrm{~kg}$, overweight is $>4 \mathrm{~kg}$, and low birth weight is $<2.5 \mathrm{~kg}$.

In the present morphometric study, placental-fetal weight ratio in normotensive and pre-eclampsia were

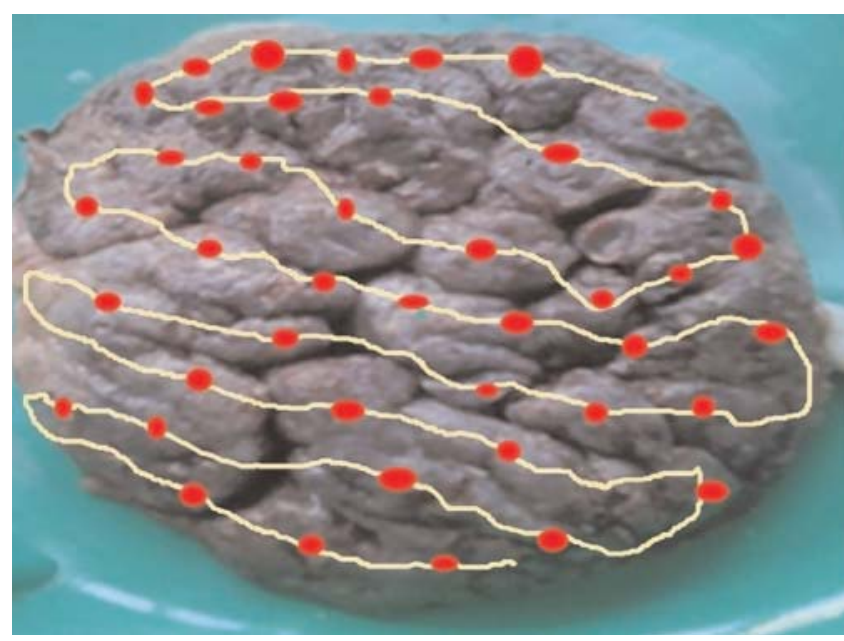

Figure 3. Counting the cotyledons of placenta. [Color figure can be viewed in the online issue, which is available at www.anatomy.org.tr] 
Table 1

Demographic and obstetric characteristics of the study subject.

\begin{tabular}{|c|c|c|c|c|c|}
\hline \multirow[b]{2}{*}{ Parameters } & & \multicolumn{2}{|c|}{ Normotensive $(n=150)$} & \multicolumn{2}{|c|}{ Preeclampsia $(n=150)$} \\
\hline & & Number & $\%$ & Number & $\%$ \\
\hline \multirow[t]{3}{*}{ Maternal age in years } & $18-25$ & 65 & 43.3 & 27 & 54 \\
\hline & $26-32$ & 65 & 43.3 & 19 & 38 \\
\hline & $33+$ & 20 & 13.3 & 4 & 8 \\
\hline \multirow[t]{2}{*}{ Gravidity } & Primigravida & 74 & 49.3 & 27 & 54 \\
\hline & Multigravida & 76 & 50.7 & 23 & 46 \\
\hline \multirow[t]{3}{*}{ Mode of delivery } & SVD & 118 & 78.7 & 26 & 52 \\
\hline & Forceps & 10 & 6.6 & 5 & 10 \\
\hline & $\mathrm{C} / \mathrm{S}$ & 22 & 14 & 19 & 38 \\
\hline
\end{tabular}

C/S: caesarean section; SVD: spontaneous vaginal delivery.

6.34:1 and 6.41:1, respectively (Table 4). This difference was not statistically significant $(\mathrm{p}=0.658)$.

Overall, there was a significant positive correlation between birth weight and placental weight, diameter, thickness and number of cotyledons $[(\mathrm{r}=0.752, \mathrm{p}=0.0001)$, $(\mathrm{r}=0.583, \mathrm{p}=0.0001),(\mathrm{r}=0.192, \mathrm{p}=0.007)$ and $(\mathrm{r}=0.647$, $\mathrm{p}=0.0001)$ ], respectively (Table 5). Comparatively, Pearson correlation test showed that birth weight was moderately correlated with placental weight $(\mathrm{r}=0.666, \mathrm{p}=0.0001)$ and number of cotyledons $(\mathrm{r}=0.566, \mathrm{p}=0.0001)$, and fairly correlated with placental diameter $(r=0.439, p=0.0001)$ in the normotensive group. In pre-eclampsia, birth weight was strongly correlated with placental weight $(r=0.809$, $\mathrm{p}=0.0001$ ) and moderately correlated with diameter, thickness and number of cotyledon. However, birth weight had no significant correlation with placental thickness in normotensive $(\mathrm{r}=0.115, \mathrm{p}=0.165)$ (Table 5).

\section{Discussion}

In the present study, the mean birth weight of preeclamptic cases $(2.62 \pm 5.87 \mathrm{~kg})$ was less than as compared to normotensive cases $(3.12 \pm 4.36 \mathrm{~kg})$. This difference was significant $(\mathrm{p}=0.0001)$. The results were in accordance with studies carried out in India $(3.14 \mathrm{~kg} \text { and } 2.44 \mathrm{~kg})^{[14]}$ and Kamataka $(3.02 \mathrm{~kg}$ and $2.61 \mathrm{~kg}) .{ }^{[15]}$ However, lower values were reported in India $(2.8 \mathrm{~kg} \text { and } 2.1 \mathrm{~kg})^{[12]}$ in both normotensive and pre-eclamptic pregnancies, respectively. This may be due to genetic, maternal weight, height and nutritional variation among study participants.

Placental-fetal weight ratio represents the balance between fetal and placental growth. It is the predictor of developing disease later in adult life. Large British cohort study suggested that having a discordance larger placenta with small baby may lead to circulatory adaptation in the fetus, altered arterial structures in the child and hypertension in the adult. This may have important implications for the prevention of adult hypertension which appear to have its origin in fetal life. ${ }^{[16]}$

Table 2

Comparison of fetal weight in normotensive and preeclamptic groups by using independent two samples t-test.

\begin{tabular}{lllllll}
\hline Variables & Group & Range & Mean & SD & t-value & p-value \\
\hline \multirow{2}{*}{ Birth weight } & Normotensive & $1.6-4.4$ & 3.12 & 0.436 & & \\
& Pre-eclampsia & $1.3-3.9$ & 2.62 & 0.587 & & 0.0001 \\
\hline
\end{tabular}

Table 3

Comparisons of birth weight category between normotensive and preeclampsia.

\begin{tabular}{lccccc}
\hline & $\begin{array}{c}\text { Normotensive group } \\
(\mathbf{n}=\mathbf{1 5 0 )}\end{array}$ & & \multicolumn{2}{c}{$\begin{array}{c}\text { Preeclampsia group } \\
(\mathbf{n}=\mathbf{5 0})\end{array}$} \\
\cline { 2 - 3 } \cline { 5 - 6 } Birth weight & $\mathbf{n}$ & $\%$ & & $\mathbf{n}$ & $\%$ \\
\hline$<2.5 \mathrm{~kg}$ & 6 & 4 & & 19 & 38 \\
$2.5-4 \mathrm{~kg}$ & 144 & 96 & & 31 & 62 \\
$>4 \mathrm{~kg}$ & 0 & 0 & & 0 & 0 \\
\hline
\end{tabular}

Table 4

Comparison of placental-fetal weight ratio between normotensive and pre-eclamptic pregnancies.

\begin{tabular}{lcccccc}
\hline & $\begin{array}{c}\text { Normotensive } \\
(\mathbf{n}=\mathbf{1 5 0})\end{array}$ & & $\begin{array}{c}\text { Preeclampsia } \\
(\mathbf{n}=\mathbf{5 0})\end{array}$ & & & \\
\cline { 2 - 3 } Parameters & Mean \pm SD & & Mean \pm SD & & t-value & p-value \\
\hline Weight of placenta & $497.95 \pm 89.1$ & & $417.6 \pm 102.41$ & 5.32 & 0.0001 \\
Birth weight & $3.12 \pm 0.436$ & & $2.62 \pm 0.587$ & 0.2 & 0.001 \\
Placental-fetal & $6.34 \pm 0.89$ & & $6.41 \pm 1.03$ & -0.443 & 0.658 \\
weight ratio & & & & & \\
\hline
\end{tabular}


Table 5

Correlation between birth weight and placental weight, diameter, thickness and number of cotyledon by using Pearson correlation test.

\begin{tabular}{lllcccc}
\hline & Variables & & Placental weight & Placental diameter & Placental thickness & Number of cotyledons \\
\hline \multirow{2}{*}{ Birth } & Over all & $r$ & 0.572 & 0.583 & 0.192 & 0.647 \\
& & $p$ & $0.0001^{*}$ & $0.0001^{*}$ & $0.007^{*}$ & $0.0001^{*}$ \\
\hline \multirow{2}{*}{ Weight } & Normotensive pregnancy & $r$ & 0.666 & 0.439 & -0.115 & 0.566 \\
& & $p$ & $0.0001^{*}$ & $0.0001^{*}$ & 0.165 & $0.0001^{*}$ \\
\cline { 2 - 7 } & Pre-eclamptic pregnancy & $r$ & 0.809 & 0.732 & 0.548 & 0.647 \\
& & $p$ & $0.0001 *$ & $0.0001^{*}$ & $0.0001^{*}$ & $0.0001^{*}$ \\
\hline
\end{tabular}

${ }^{*}$ Correlation is significant at $\leq 0.05$ levels (2-tailed)

The normal birth weight to placental weight ratio ranged from 6.5 to 7.1 at term $37-42$ weeks of gestation. In cases with pre-eclampsia, this ratio was found to be significantly $(\mathrm{p}=0.001)$ smaller as compared to normotensive cases 6.60 vs. $7.40{ }^{[16]}$

In the present study, the mean feto-placental weight ratio was $6.34 \pm 0.89$ in normotensive cases and $6.41 \pm 1.03$ in pre-eclampsia. The difference was not statistically significant $(\mathrm{p}=0.658)$. This is in accordance with findings noted in Rajindra Hospital in Punjab, India which found almost constant fetal placental weight ratio in normotensive $(6.308 \pm 0.364)$ and pre-eclamptic $(6.343 \pm 0.953)$ pregnancies at $\mathrm{p}=0.8598$. $^{[13]}$

In the present study birth weight was positively correlated with placental weight $(\mathrm{r}=0.75, \mathrm{p}=0.0001)$, diameter $(\mathrm{r}=0.583 . \mathrm{p}=0.0001)$, thickness $(\mathrm{r}=0.192, \mathrm{p}=0.007)$, and number of cotyledon $(\mathrm{r}=0.647, \mathrm{p}=0.0001)$ in both normotensive and pre-eclamptic group as a whole (Table 5). This finding of Pearson correlation indicates that when placental weight, diameter, thickness and number of cotyledons increase, birth weight also increases and vice versa.

Comparatively, Pearson correlation showed that birth weight was moderately correlated with placental weight and number of cotyledons and fairly correlated with placental diameter in the normotensive, while in pre-eclampsia, it was strongly correlated with placental weight and moderately correlated with diameter, thickness and number of cotyledons. However, birth weight did not have a statistical significant $(\mathrm{p}=0.165)$ correlation with placental thickness in the normotensive group (Table 5).

In normotensive cases, placental weight is directly proportional to birth weight. When birth weight becomes large, placental weight and size also increase to accommodate the large fetus. As placental size increases, the placental thickness becomes small. This result was supported by reports from Pakistan $(r=0.413, p=0.003)$, ${ }^{[17]}$ Norwich $(\mathrm{r}=0.78, \mathrm{p}=0.001)^{[18]}$ and India $(\mathrm{r}=0.759$, $\mathrm{p}<0.01)^{[8]}$ which showed that birth weight was significantly associated with placental weight. This confers that the higher the birth weight, higher is placental weight and vice versa.

Another morphological comparative study of placenta in normotensive and pre-eclampsia was performed in Kamataka; India showed that mean placental weight $(r=0.96$ and $r=0.98)$, diameter $(r=0.92$ and 0.92$)$ and number of cotyledons ( $\mathrm{r}=0.9$ and 0.86 ) were strongly correlated with fetal weight. ${ }^{[19]}$

There are some limitaions for this study. Since this study was conducted in a health institution, placentas from both groups who delivered at home could not be studied. Although the range of $37-42$ weeks is a large interval in which the dimensions and weight of the placenta continues to grow, this study does not consider the normotensive and pre-eclamptic groups in terms of distribution of the delivery time within 37-42 weeks. Also, some pre-eclamptic cases were diagnosed at the time of delivery and others were diagnosed at variable times between 34 to 35 weeks as the individual mother told. Due to this, it was difficult to determine for how long the placenta was exposed to the disease. Therefore, this study did not consider the length of time in which placenta exposed to pre-eclampsia.

\section{Conclusion}

Birth weight was significantly reduced in pre-eclamptic pregnancies as compared to normotensive pregnancies. Morphology of placenta such as weight, diameter and number of cotyledons were correlated with birth weight in both groups, but placental thickness was only correlated with birth weight in pre-eclampsia, but not in the 
normotensive group. Placental-fetal weight ratio did not have a significant difference between the two groups. Examination of placental morphology prenatally by using ultrasound and observation immediately after delivery is important for better management of such and subsequent pregnancies.

\section{Acknowledgements}

The authors gratefully acknowledge Bahir Dar University, University of Gondar, data collectors, and study participants involved in the study.

\section{References}

1. Mardi K, Sharma J. Histopathological evaluation of placentas in IUGR pregnancies. Indian J Pathol Microbiol 2003;2:1-4.

2. Jain A, Sharma D, Sharma V, Baweja S, Jain R. Study of placental weight in normal and pre-eclamptic pregnancies and its correlation with birth weight. International Journal of Medical Research and Review 2016;4:2-8.

3. Goswami P, Memon S, Rathore MI. Foeto-placental weight relationship in normal pregnancy and pregnancies complicated by pregnancy induced hypertension and abruption of placentae. International Journal of Research in Medical Sciences 2015;3:10814.

4. Sirpurkar M, Anjankar VP. Study of correlation between placental morphology and adverse perinatal outcome in different conditions affecting pregnancy. International Journal of Reproduction, Contraception, Obstetrics and Gynecology 2015;4:1165-8.

5. Kambale T, Iqbal B, Ramraje S, Swaimul K, Salve S. Placental morphology and fetal implications in pregnancies complicated by pregnancy-induced hypertension. Medical Journal of DY Patil University 2016;9:341-7.

6. Gupta C, Harode HA, D'souza AS, Sharma A. A morphological and morphometric study of placenta with its clinical implications. Tropical Journal of Medical Research 2015;18:85-8.

7. Susmita S, Lopamudra N, Shashi SB, Prafulla KC. Morphometric study of placenta of full term new born \& its relation to fetal weight: a study in Tertiary Care Hospital of Odisha. Journal of Evolution of Medical and Dental Sciences 2015;4:742-7.
8. Londhe PS, Mane AB. Morphometric study of placenta and its correlation in normotensive and hypertensive pregnancies. International Journal of Pharma and Bio Sciences 2011;2:429-37.

9. Aremu AA, Atanda OO, Adeomi AA. Newborn birth weight and placental parameters in normal human pregnancies. Journal of Pharmaceutical and Biomedical Sciences 2013;30:23-7.

10. Sankar KD, Bhanu PS, Ramalingam K, Kiran S, Ramakrishna BA. Histomorphological and morphometrical changes of placental terminal villi of normotensive and preeclamptic mothers. Anat Cell Biol 2013;46:285-90.

11. Gundalli SM, Kolekar R, Sunita VN, Nandurkar V. Placenta in eclampsia and pre-eclampsia. IOSR Journal of Dental and Medical Sciences 2015;14:46-51.

12. Shevade S, Arole V, Vaishaly B, Paranjape V. Placental morphology and fetal outcome in preeclampsia and normotensive pregnancies. IOSR Journal of Dental and Medical Sciences 2015;14:11-5.

13. Kaur P, Kaushal S, Singh K, Sharma A. Placental weight, birth weight and fetal outcme in preeclampsia and normotensive pregnancies. International Journal of Plant, Animal and Environmental Sciences 2013;3:30-34.

14. Singh S, Gugapriya TS. A cross sectional morphometric study of hypertensive with normal placentae and its correkation with fetal outcome. International Journal of Anatomy and Research 2014;2:437-42.

15. Raghavendra AY, Vinay KV, Pai V. A study of placental weight and fetal outcome in different grades of pregnancy induced hypertension. International Journal of Anatomy and Research 2014;2:625-9.

16. Pathak S, Sebire NJ, Hook L, Hackett G, Murdoch E. Relationship between placental morphology and histological findings in an unselected population near term. Virchows Arch 2011;459:11-20.

17. Ullah E. Unfavorable effects of pre-eclampsia on the morphology of the placenta. Pakistan Journal of Medical and Health Sciences. 2013;7:207-11.

18. Pathak S. Morphological and histological placental characteristics in relation to pregnancy outcome in an unselected population. Doctoral dissertation, University of East Anglia, Norwchich, Norfolk, UK, 2010.

19. Girish BL, Nandagopal KM, Padmini CP, Mahesh SH, Ragunatha S, Srinath S. A morphometric comparative study of placenta in normal and preeclampsia pregnancies delivering at 36 to 38 weeks of gestation and its impact on birth weight. Journal of Evolution of Medical and Dental Sciences 2015;4:14444-50.

Correspondence to: Shibabaw Tedla Tiruneh, MSc Department of Human Anatomy, School of Medicine, College of Medicine and Health Sciences Bahir Dar University, Bahir Dar, Ethiopia Phone: +251918375 554 e-mail: shibabawtedila@gmail.com Conflict of interest statement: No conflicts declared.

This is an open access article distributed under the terms of the Creative Commons Attribution-NonCommercial-NoDerivs 3.0 Unported (CC BY-NCND3.0) Licence (http://creativecommons.org/licenses/by-nc-nd/3.0/) which permits unrestricted noncommercial use, distribution, and reproduction in any medium, provided the original work is properly cited. Please cite this article as: Tiruneh ST. Correlation between gross morphology of the human placenta and birth weight in normotensive and pre-eclamptic pregnancies in Northwest Ethiopia. Anatomy 2018;12(1):27-32. 